\title{
Cohort Fertility Changes and Period Fertility in 1960-1990 in Finland
}

\section{IRMA-LEENA NOTKOLA}

\author{
Senior Assistant \\ Department of Community Health \\ and General Practice \\ University of Kuopio \\ Kuopio, Finland
}

\begin{abstract}
In Finland, like in most European countries, the total fertility rate declined from a level of 2.5 births per woman in the middle of the 1960s below the replacement level of 2.1 births during the late sixties. This change has been called Europe's second demographic transition. This paper aims to describe the changes in cohort fertility during and after this transition. The cohorts whose fertility is examined include the cohorts of women born between 1923-24 and 1961-62. The cohort fertility data are from unpublished tables of Statistics Finland.

Total fertility decreased from 2.6 births per woman in the cohort 1923-24 to the level of 1.8-1.9 births per woman in the cohorts 1943-44 and has stayed at this level in younger cohorts. The most prominent change in fertility behavior in recent years has been delaying births later in life. This transformation has been going on since the cohorts born in the middle of the 1940s. In calendar time this transformation started in the late sixties which suggests that the new contraception methods played an important role in it. Cohort fertility results are used in interpreting period fertility trends and variability in the last decades.
\end{abstract}

Keywords: second demographic transition, fertility decline, cohort fertility, Finland

\section{Introduction}

In most Western European countries total fertility dropped under the replacement level of 2.1 at the end of the 1960s or at the beginning of the 1970s. Van de Kaa (1987) has called this change Europe's second demographic transition. In Finland period total fertility had declined since the beginning of the $1950 \mathrm{~s}$, but this decline accelerated from the mid-1960s, when total fertility was still 2.5 children per woman. The decline in fertility continued up to 1973 , when total fertility was only 1.5 . It then remained around 1.6-1.7 children until the end of the 1980s, when it began a slight rise.

In several Finnish articles written in the 1970s and 1980s, the explanation for these fertility changes was sought in the unusual behavior of the baby boom cohorts (the large age groups born after the war, in 1946-1949): the small fertility at the begin- 
ning of the 1970s was explained by the baby boom cohorts postponing having children and the rise in fertility in the 1980 s by these cohorts then having the children they had not had earlier (Lindgren 1977; Central Statistical Office 1978; Wiman 1978; Lindgren and Ritamies 1981; Lindgren 1984). These interpretations were based on Easterlin's hypothesis about the low fertility of the large generations (e.g. Easterlin 1978; 1987). According to Easterlin the decision to have children is made on the basis of how large one's potential income is compared to one's expected standard of living. Potential income depends on current income and predictable future income, which again depends mainly on career prospects. Expectations concerning one's standard of living are based on the standard of living in one's childhood and youth. In making decisions about having children, young people compare their expected standard of living with potential income: the larger the potential income compared to the expected standard of living, i.e. the greater the relative income, the greater is fertility. The size of the cohort is an essential factor affecting relative level of income. Large cohorts fill the job market, leading to stiffening competition for jobs, slower career development and lower salaries. The size of the cohort compared to the size of the previous generation indicates this generation's potential income compared to their parents' income, in other words their expectations concerning their standard of living. Thus, according to the hypothesis, a large youth cohort relative to the parental cohort leads to low income and low fertility, and a small youth cohort relative to the parental cohort leads to a high relative income and high fertility.

This article will examine the development of fertility after 1960 using cohort fertility rates. By examining cohort fertility, we will discover what changes in fertility behavior are hidden behind the changes in period fertility and we can then perhaps more easily understand and explain these changes. On the basis of these results we can also re-estimate the role of the baby boom cohorts in the changes in fertility in the 1960 s-1980s as well as the effect of other factors on fertility.

\section{The development of period-specific fertility in 1960-1990}

\section{Total fertility}

In Finland period total fertility decreased steadily throughout the 1950 s and in the early 1960 s. During the period 1950-1965 total fertility decreased from 3.2 children to 2.5 children per woman. The decline in total fertility clearly accelerated in the mid1960 s. Total fertility decreased steeply up to the beginning of the 1970 s, so that total fertility was only 1.5 children per woman in 1973 (Figure 1). After 1973 total fertility remained at the 1.6-1.7 level until the end of the 1980s. In just the last few years fertility has again risen slightly, so that the current total fertility rate is about 1.8 .

\section{Age-specific fertility}

The age-specific fertility rates for over-24-year-olds decreased in Finland throughout the 1950 s. The fertility of these age groups continued to diminish in the 1960 s (Figure 2). In addition, fertility among the 20-24-year-olds, which had increased in the 1950 s, started to decrease in the 1960s. Thus, fertility declined in all age groups except for the 15-19-year-olds throughout the 1960s and in the 1970s, up till 1973. Fertility among the 25-29-year-olds and older age groups started to increase in 1974 and this rising tendency has continued in these age groups into the 1990s. On the other hand, fertility among the 20-24-year-olds has continued to decline up to the end of 
F i g u r e 1. Period and cohort total fertility in 1960-1990

Children per woman

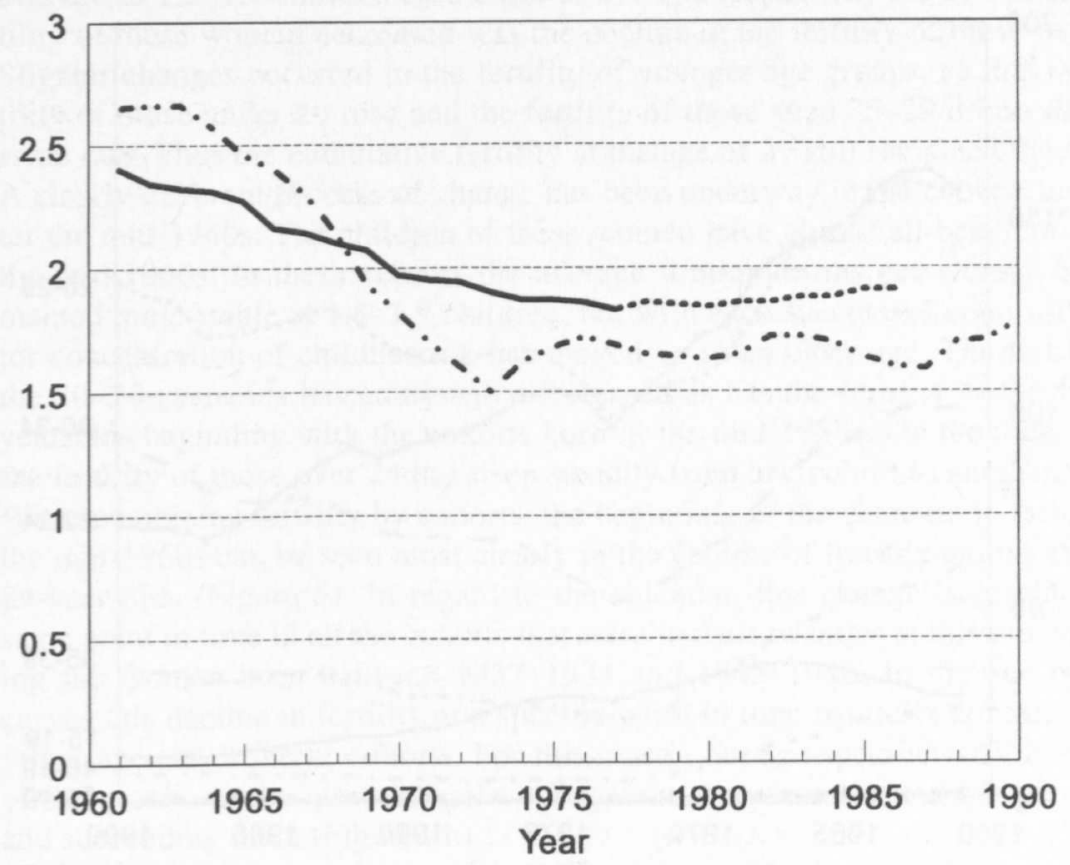

Period rate Cohort rate Estimated cohort rate

Notes: Cohort rates are at the points where the cohorts attained the age of 29.5. For those cohorts whose cumulative fertility was known at least up to age 35 but whose fertile period was not completed by the year 1992 values were filled up by estimates based on the age-specific fertility rates of the year 1992. These rates are called »estimated cohort rates». Source: Statistics Finland, population statistics and unpublished data.

the 1980 s. From the beginning of the 1970 s the fertility of women aged 15-19 has also decreased.

The shifting of the focus of fertility to older age groups can also be seen in the rise in the age at first birth. In Finland the median age of women at first birth still continued to decrease at the beginning of the $1960 \mathrm{~s}$, but since the end of the $1960 \mathrm{~s}$ it has risen continuously: in 1965 the median age of women at first birth was 22.9 years, and in 1990 the corresponding age was 26.5 years. Elsewhere in Western Europe development has been similar and in most countries the average age at first birth is currently over 25. In most Eastern European countries there has been no corresponding postponement of first childbirth, and women give birth to their first child clearly under 25 years of age (Council of Europe 1993).

\section{Changes in cohort fertility}

Cohort fertility statistics are not presented in annual population statistics publications in Finland. Cohort fertility data are available from Statistics Finland but no analysis has been made since the 1970s (Lindgren 1975; Fougstedt 1977). 
F i g u r e 2. Age-specific fertility rates in 1961-1990

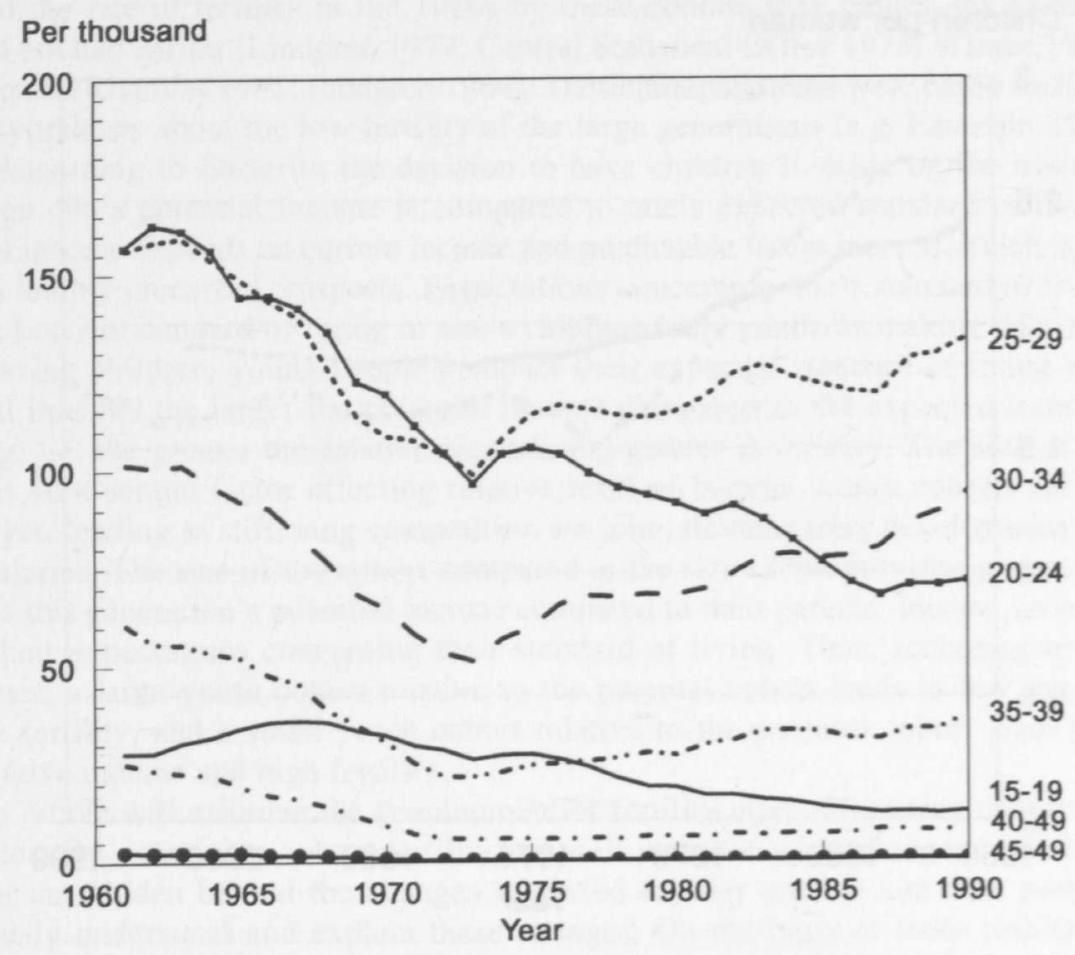

Source: Statistics Finland, population statistics

The cohorts chosen for closer examination in this study are the female cohorts of 1923-1924 to $1965-1967$. Since the period fertility of $1960-1990$ is composed mainly of the fertility of these women. Figures 3-5 show the age-specific fertility of the 1923-1924 to 1965-1967 cohorts in various ways. In Figures 3 a-c the 1-year agespecific fertility rates have been placed on the calendar time axis. These figures clearly illustrate the age-specific cohort fertility changes in the cohorts which »explain» the low fertility at the end of the 1960 s and in the early 1970s. The changes in age pattern of fertility can be seen most clearly in Figures $4 \mathrm{a}-\mathrm{c}$, which show age-specific fertility rates for the cohorts so that age is on the horizontal axis. Figure 5, on the other hand, describes the cumulative fertility of the cohorts according to calendar time. It demonstrates, for example, the changes in the completed fertility of cohorts ending childbearing at different points in time. In addition it shows quite clearly the main period-specific effects, i.e. the concurrent codirectional changes among cohorts.

It can be concluded from the figures that the female cohorts which were at childbearing age in the period 1960-1990 can be divided into three different groups according to the development of change in the fertility model:

- cohorts, which had reached the age of 30 by the mid-1960s (I).

- cohorts, which had reached the age of 20 after the mid-1960s (II),

- »transitional cohorts», which are composed of women who were 20-29 years of age in the mid-1960s (III).

(I) The cohorts which had reached the age of 30 by the mid-1960s include female cohorts born between 1923-1924 and 1935-1936. The completed fertility decreased in these cohorts from 2.6 children to 2.3 children. In all of these cohorts 
women married young (about $60 \%$ were married at the age of 24, Myrskylä 1976, 26 ) and fertility was high in the young age groups: women had given birth to an average of 1.6-1.7 children by the age of 29 . The reason why the completed fertility of these women decreased was the decline in the fertility of those over 30 . Slighter changes occurred in the fertility of younger age groups, so that the fertility of those under 20 rose and the fertility of those aged 25-29 dropped at the same rate. Thus the cumulative fertility at the age of 29 still remained the same.

(II) A clearly different process of change has been underway in the cohorts born after the mid-1940s. The children of these women have almost all been born after the mid-1960s. In these cohorts the average lifetime births per woman has remained quite stable at 1.8-1.9 children, but with each successive cohort the major concentration of childbearing has moved on to an older age. The fertility of the 20-24-year-olds has continually decreased as has the fertility of the 15-19year-olds beginning with the cohorts born in the mid-1950s. On the other hand, the fertility of those over 24 has risen steadily from one cohort to another.

(III) When examining fertility by cohorts, the beginning of the decrease in fertility in the mid-1960s can be seen most clearly in the decline of fertility among the 20 29-year-olds (Figure 5). In regard to the calendar, this change occurred at the same point in time in all the cohorts that were in their twenties at this time, meaning the women born between 1937-1938 and 1945-1946. In the age-fertility curves this decline in fertility at a specific point in time naturally appears at different ages in different cohorts. For this reason the age-specific fertility curves of these cohorts are quite irregular - in contrast to the cohorts both preceding and succeeding them (Figure $3 \mathrm{~b}$ ).

In the curves showing the 1-year age-specific fertility rates in the transitional cohorts (Figure 3b), a second definite period-specific effect can be seen at the beginning of the 1970s, and most clearly in 1973. Especially in cohorts which were 20-29 years of age at that time, fertility declined for a short period. As a result, especially these cohorts had a double-peaked fertility model.

The fertility in the older ages began to rise gradually in these transitional cohorts, but it did not rise high enough, however, to compensate for the decrease in the fertility of the 20-29-year-old age groups. Instead the total number of births declined from 2.1 children to 1.9 children per woman. Thus it was specifically in these cohorts that fertility dropped below replacement level.

\section{Cohort fertility changes and period fertility from 1960 to 1990}

If the fertility patterns of cohorts which are in childbearing age at the same time differ from each other, period fertility rates do not represent the fertility of any actual female cohort. Similarly, the period total fertility rate also provides a misleading picture of the actual total number of children born to these female cohorts. In Finland the fertility model of the cohorts has changed continuously over the last thirty years. This transition caused discrepancies between cohort and period total fertility trends. According to Figure 1 the period rates for the 1960 s overestimate actual fertility. At that time the majority of the cohorts of childbearing age were cohorts where fertility decreased from one cohort to another in the older age groups. Thus period rates for each age group overestimated the fertility of the older age groups and produced too high a total fertility rate. Right at the beginning of the 1970 s the situation took an opposite turn. Since then the period rates have underestimated cohort fertility. The prevailing trend of change in the cohort fertility model has been the postponing of childbearing to a later age. Thus a total fertility based on period rates in a given year has underesti- 
Fi g u r e 3a-c. Age-specific fertility rates for 1-year age groups for selected birth cohorts of women born between 1923-24 and 1965-66, placed according to respective calendar years.

Per thousand

a) Cohorts $1923-24 \ldots 1937-38$

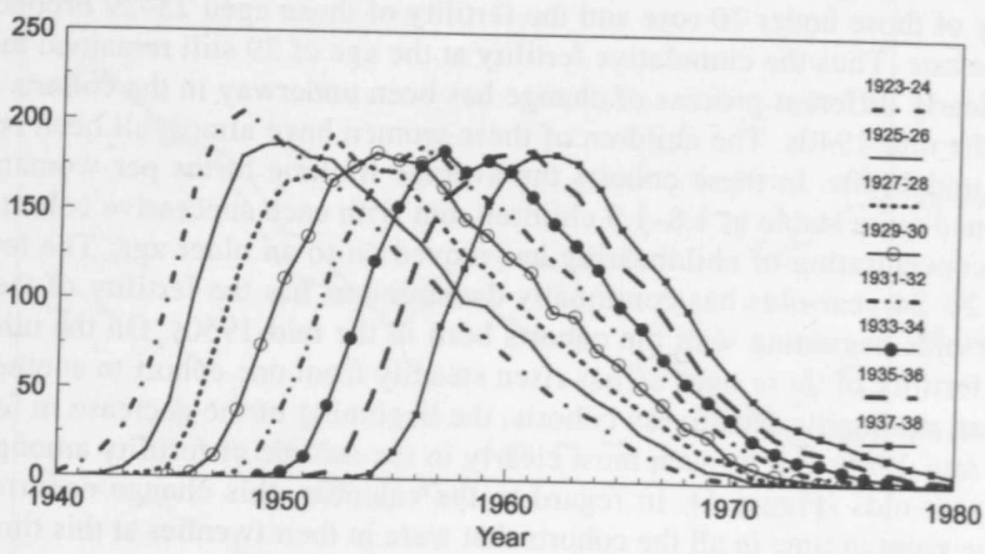

b) Cohorts $1937-38 \ldots 1951-52$

Per thousand

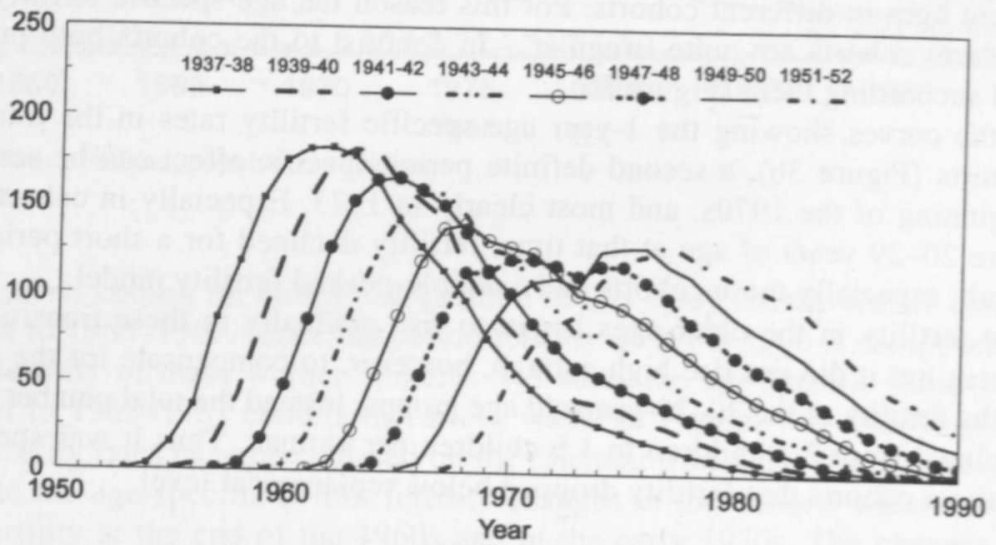

Per thousand

c) Cohorts $1951-52 \ldots 1965-66$

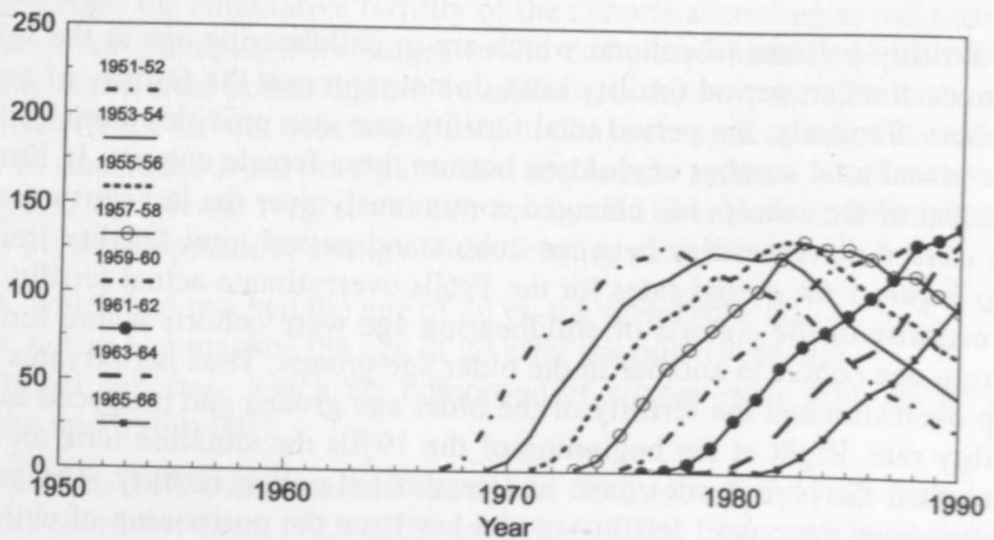

Source: Statistics Finland, unpublished data 
Fig u r e 4a-c. Age-specific fertility rates for 1-year age groups for selected birth cohorts $1925-26 \ldots 1961-62$

a) Cohorts $1925-26,1931-32$ and $1937-38$

Per thousand

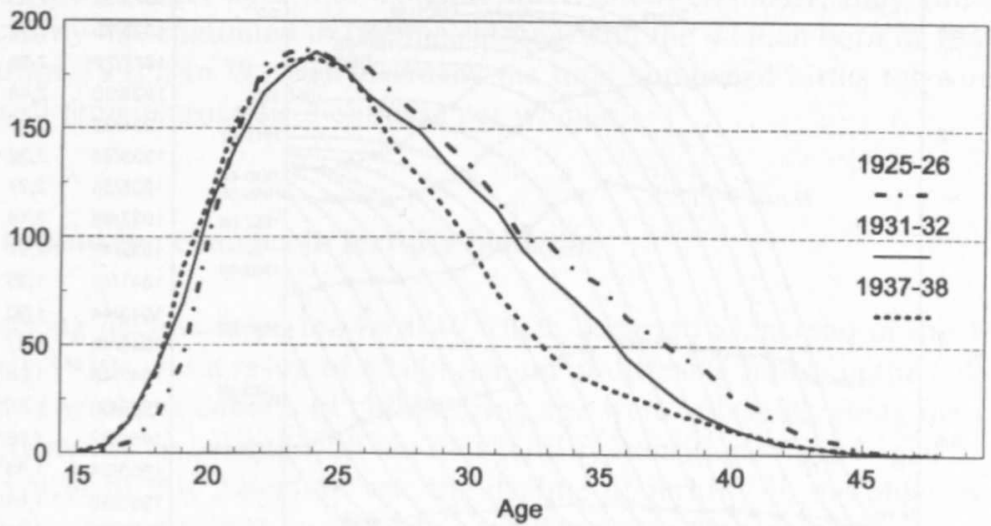

b) Cohorts $1937-38,1943-44$ and $1949-50$

Per thousand

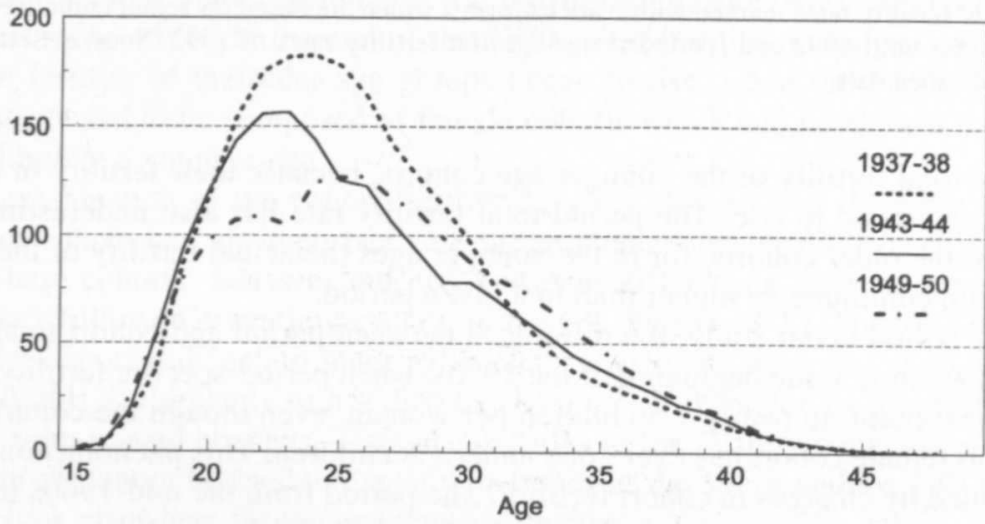

c) Cohorts 1949-50, 1955-56 and 1961-62

Per thousand

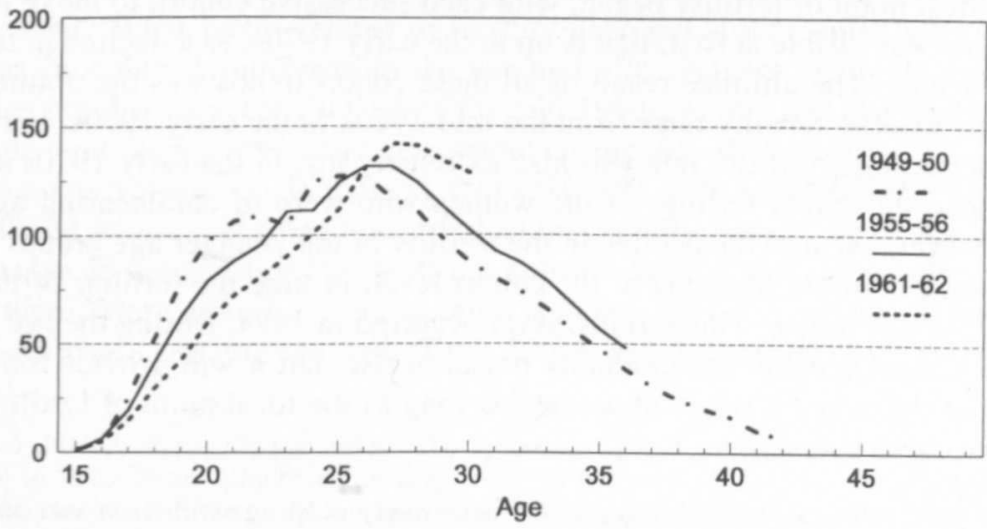

Source: Statistics Finland, unpublished data 
F i g u r e 5. Cumulative age-specific fertility rates for birth cohorts of women born between 1923-24 and 1965-66, placed according to respective calendar years

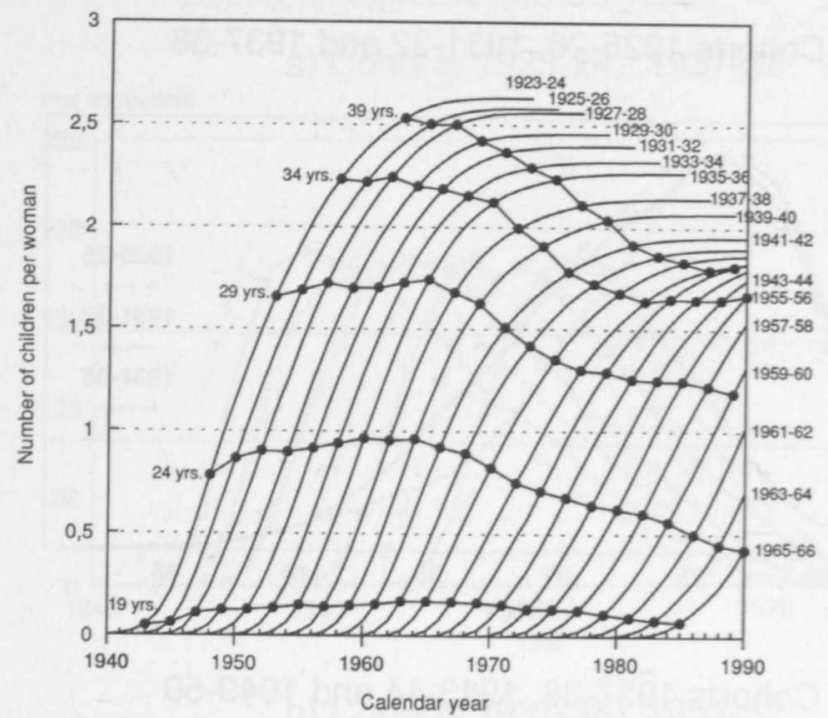

\begin{tabular}{|ll|}
\hline Cohort & $\begin{array}{c}\text { Total } \\
\text { fertility rate }\end{array}$ \\
$1923 / 24$ & 2,63 \\
$1925 / 26$ & 2,58 \\
$1927 / 28$ & 2,56 \\
$1929 / 30$ & 2,46 \\
$1931 / 32$ & 2,40 \\
$1933 / 34$ & 2,32 \\
$1935 / 36$ & 2,27 \\
$1937 / 38$ & 2,14 \\
$1939 / 40$ & 2,07 \\
$1941 / 42$ & 1,95 \\
$1943 / 44$ & 1,90 \\
$1945 / 46$ & 1,87 \\
$1947 / 48$ & 1,83 \\
$1949 / 50$ & $1,85^{*}$ \\
$1951 / 52$ & $1,86^{*}$ \\
$1953 / 54$ & $1,88^{*}$ \\
$1955 / 56$ & $1,91^{*}$ \\
$1957 / 58$ & $1,92^{*}$ \\
$1959 / 60$ & $1,92^{*}$ \\
\hline & \\
\hline
\end{tabular}

Notes: Total fertility rates marked with * are estimates which are based on actual cumulative fertility of each cohort until 1992 and (periodic) age-specific fertility rates of 1992. Source: Statistics Finland, unpublished data

mated the total fertility of the younger age cohorts, because their fertility in the older ages has continued to rise. The period total fertility rate has also underestimated the fertility of the older cohorts, for in the younger ages the actual fertility of these women had been continuously higher than in a given period.

In the period under study, the difference between period and cohort total fertility was at its greatest at the beginning of the 1970 s, when period-specific fertility dropped to its lowest point, to nearly 1.5 children per woman, even though the completed fertility of no female cohort has ever gone under 1.8 children. This phenomenon also can be explained by changes in cohort fertility. The period from the mid-1960s to the early 1970 s was a time when a transition in the fertility model was still underway in the older age groups at the cohort level, one where fertility after the age of 30 declined, in particular. At the same time, in the younger cohorts entering their childbearing period the focal point of fertility began, with each successive cohort, to move to an older age. This was visible at first, that is up to the early $1970 \mathrm{~s}$, as a decline in the fertility of the young. The ultimate result of all these cohort trends was the diminishing of all the age-specific fertility rates from the mid-1960s to the early 1970 s. For this reason the period total fertility rate was also extremely low in the early 1970 s and it underestimated the actual fertility of the women who were of childbearing age at that time. However, because the decline in the fertility of the younger age groups signified a postponement of childbearing at the cohort level, in time the fertility of those over the age 25 began to rise. This turning point occurred in 1974. During the last two decades period total fertility has gradually began to rise, but it will provide too negative a picture of the actual fertility of women as long as the focal point of fertility continues to move to a later age. ${ }^{1}$

1 The postponement of childbearing to an increasingly older age with each successive cohort appears, as far as we now know, to have stopped with the cohorts born in the mid-1960s, that is women 
Postponing childbearing has been the major change in fertility behavior during the last few decades in Finland. Completed fertility has not really changed at all for the cohorts born after the mid-1940s. Although the age-specific fertility change trends elsewhere in Europe have been quite similar to those in Finland, the rise in the fertility of the older ages has not been sufficient everywhere to compensate for the decline in the fertility of the younger ages. For example, in Western Germany, Italy and Denmark cohort fertility has continued to decline starting with the women born in 1940 (Council of Europe 1991). In Western Germany the total number of births for women born in 1955 will remain around 1.6 children per woman.

\section{Factors behind the changes in fertility behavior}

The strong decline in period fertility which occurred at the end of the 1960 s and in the early 1970 s was a result of a culmination of differing trends in the cohort fertility model. The oldest cohorts of childbearing age were still undergoing the change in the fertility model associated with the first fertility transition which began in the early 1900s. Typical of this transition was the decline of fertility in the older age groups with each successive cohort. In contrast, a trend began in the younger age groups where childbearing has continually been postponed to an older age. At first this development was visible in the period-specific rates only as a decline in the fertility of young women. As a result of these trends period-specific fertility diminished very strongly from the mid-1960s up to 1973 . At the end of the 1970 s total fertility no longer declined, because the fertility of the older age groups began to rise, when the majority of these age groups began to be composed of female cohorts which had postponed the birth of their children at a younger age.

The examination of the cohort fertility does not suggest that the baby boom cohorts would have had an important role in the changes in fertility in the 1960 s and 1970s. These cohorts' behavior did not, however, differ from their adjacent cohorts, instead they followed prevailing general trends (cf. Finnäs 1988). The total fertility of the largest cohort did remain marginally under that of its adjacent age cohorts, but apparently this - ultimately minor difference - can be explained by a cohort encountering of time-related changes. Thus peculiarities in the fertility behavior of the baby boom cohorts cannot be used to explain the trends of the 1960s and the 1970s, instead we must look elsewhere for the generator of change.

The feature most characteristic of the change in fertility behavior during the last few decades has been the postponement of childbearing to a later age. This development began in the mid-1960s. What period-specific factor could explain this change and its timing? What factor related to fertility changed at that time? One important factor was probably the increase in the use and effectiveness of contraception. The pills came onto the market in Finland by the mid-1960s, as they did elsewhere in Western Europe, and their use became very common rapidly. In the early 1970s the IUD also came into very wide use in Finland. (Notkola 1994.) The introduction on the market of the pill and its use and spread occurred so much at the same time as the beginning of the change in the fertility model that it appears evident that an association exists between them. More effective contraception also provides an explanation for the special features characterizing the end of the 1960 s and the early 1970 s, such as a de-

who entered childbearing age in the 1980s. The 1-year age-specific fertility rates for the cohorts born in 1964-64 to 1970-71 are almost identical up to 1992. Whether this is merely a question of a temporary static phase or that the postponement of childbearing to an increasingly older age has stopped at the population level will remain to be seen in the $1990 \mathrm{~s}$. 
cline in the birth rate despite an increase in nuptiality and a lengthening of the period between marriage and first birth (see Notkola 1994).

Even before the mid-1960s there were, of course, various mechanical and chemical contraceptives available, but their users had often experienced contraception failure (see Leppo 1978). Thus in a survey made in 1971 about one half of the married women said their first pregnancy had begun too early or had been unwanted, and also higher order pregnancies were often found mistimed or unwanted (Ritamies and Visuri 1975). Thus there was a »social demand» for effective contraceptives, which explains the rapid spread of their use in the 1960s and the 1970s. The use of the pill (and the IUD) means almost a total cessation of contraception failure, which makes it easy to understand that when the use of these methods spread, it was reflected rapidly in the fertility rates. The changes were most evident in the young age groups, where new means of contraception were accepted more rapidly than in the older age groups.

Although the use of effective contraceptive methods probably explains the timing of the change in the fertility model, and thus also the strong decline in period fertility from 1965 to 1973 , the improved effectiveness of contraception alone can hardly be enough to explain the rise in the age at first birth well into the 1980 s. Apparently the motives for having children have also undergone change. The assumption can be made that the desire to postpone childbirth in the 1970s and 1980s has been augmented by the increase in education and employment among women. However, effective birth control methods have been a necessary prerequisite for the family formation model which has spread increasingly during the last few decades, one where people enter a relationship when they are young, but postpone childbearing until close to the age of 30. Such a pattern of behavior would not be possible to its current extent using only chemical and mechanical contraceptives, but the pill and the IUD have made a lifestyle like this feasible.

\section{The $\mathbf{1 9 7 0}$ abortion law as an additional explanation for the fertility changes in the early 1970s}

The annual number of abortions in Finland was about 5,000-6,000 in the 1960 s. After the liberalization of the abortion law (June 1, 1970), there was a very rapid and extreme rise in the number of abortions. Already in 1970, the year the law came into force, over 14,000 abortions were performed and in 1971 already almost 21,000 . The peak year was 1973 , when the number of abortions rose to 23,400 . During the rest of the decade, starting in 1973, the number of abortions decreased rapidly and this decrease continued in the $1980 \mathrm{~s}$. At the end of the 1980 s only 13,000 abortions were performed annually. The increase in abortions in the years after the abortion law was passed was actually not as strong as one might read from the abortion statistics, for the statistics do not include illegal abortions performed before the 1970 abortion law. Minimum estimates of the annual number of illegal abortions at the end of the $1960 \mathrm{~s}$ vary from about 1,000 abortions to about 2,800 abortions and maximum estimates correspondingly from 8,500 abortions to 10,600 abortions (Lahti 1973). The abortion statistics thus exaggerate the increase in abortions in the first few years after the new abortion law. On the other hand, even if illegal abortions are taken into consideration, the fact remains that the total number of abortions increased with the passing of the abortion law (Lahti 1973).

The development of the number of live births in the early 1970s in Finland followed the inverse of the development in the number of abortions: the number of births decreased until 1973 and started to increase in 1974 (Figure 6). Even though the number of births decreased when abortions increased, it is, in fact, difficult to find clear proof 
Fi g u r e 6. Number of live births and number of abortions, 1965-1990

Thousands

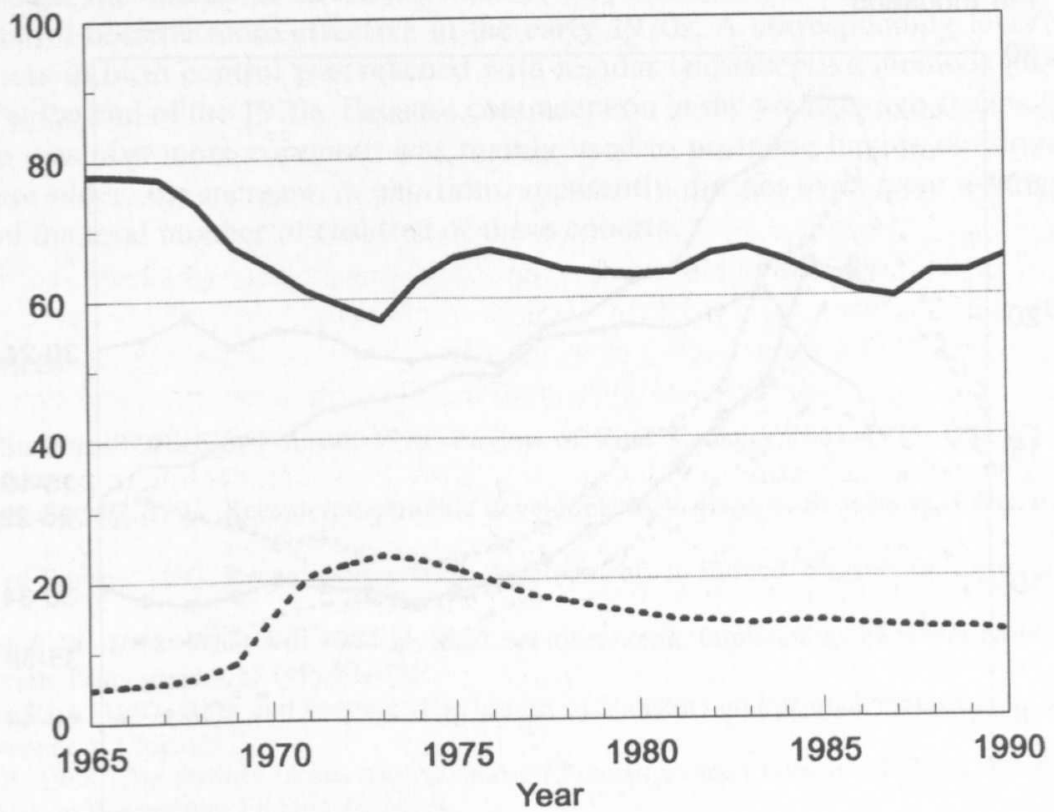

Births Abortions

Sources: Statistics Finland, population statistics

in the number of births that the new abortion law would have decreased the birth rate. The decline in fertility (and in the birth rate) in the early 1970s was namely a continuation of the decline in fertility which had begun at the end of the 1960s, and which is quite evidently related to the increase in the effectiveness of contraception. One could assume that if the increase in abortions would have decreased the birth rate, the decline in the birth rate should have increased quite markedly in 1971 and 1972, for about 12,000 more legal abortions were performed in 1971 than in 1969 . However, the largest decline in the annual number of births occurred already in the 1960 s and the changes in the annual numbers of legal abortions do not seem to predict at all the decline in the number of births in 1967-1975.

It is thus difficult to see that the annual fluctuations in the number of births and the birth rate in 1965-1975 would reflect the number of abortions in the corresponding years, nor can a comparison of the number of births and the number of abortions be used to show that the spread of abortions would have decreased the birth rate. Thus can it be assumed that the abortion boom at the beginning of the 1970s did not influence the birth rate? In assessing the effect of the abortion law, the number of births as well as the general birth rate are poorly suited for describing the development of fertility, because they are affected also by the age structure of the population. On the other hand, age-specific fertility rates, for example, provide a clearer picture of fertility behavior changes. For comparison we can examine age-group-specific abortion rates.

After the abortion law reform, all 5-year age-group-specific abortion rates for the 20-44-year-old women rose very rapidly at first, but then after a few years they again 
Fig u re 7. Legal abortion rates by age of woman at termination 1970 per 1000 women.

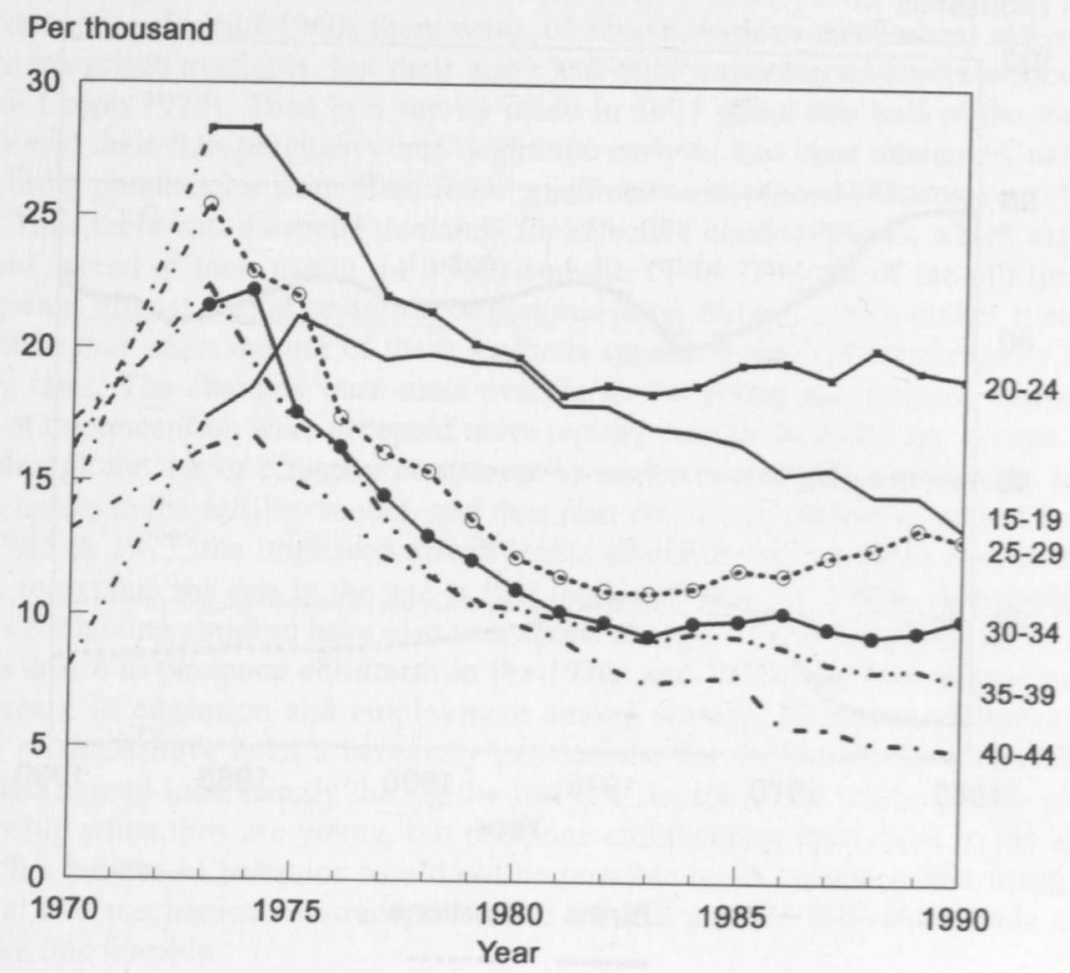

Sources: Henshaw and Morrow 1990; Rasimus 1993

began to decline (Figure 7). The abortion rate among the 15-19-year-olds also rose considerably in the early 1970 s, but in contrast to the older age groups, the incidence rate remained at the new higher level throughout the 1970 s and it was not until the 1980 s that it decreased slightly.

The changes in fertility at the end of the 1960 s and in the early 1970 s can definitely be explained mainly by increasing the effectiveness of contraception, especially by the spread of the use of the pill and the IUD. There are some features in the development of fertility at the beginning of the 1970 s, however, which can be explained more plausibly with the new abortion law and the resulting temporary strong increase in abortions. The use of birth control pills continued to spread from the mid-1960s on and the use of the IUD from the early 1970 s on, so that contraception can be assumed to have become continuously more effective relatively constantly over time. The increase in the effectiveness of contraception can thus be assumed to have changed fertility behavior in the same direction from the mid-1960s on as long as contraception continued to increase in effectiveness, apparently until well into the 1980 s. One could assume that these changes would be evident in the fertility rates as a gradual, relatively even change. However, especially in the cohort age-specific fertility rates, we can see that all cohorts that were 20-34 years of age in the early 1970s display an »extra hump» in the early 1970s, culminating in the year 1973 (see Figure 3b). The spread of abortions seems to provide an explanation for these special features of development in the early 1970 s. There was a very rapid increase in abortions in the early 1970 s up to 1973 , after which they again rapidly decreased. 
Thus it seems that the spread of abortions strengthened the decline in fertility in the early years of the $1970 \mathrm{~s}$. The increase in abortions remained very short-term, however, so that the spread of abortions mainly temporarily increased the rate at which birth control became more effective in the early 1970s. A corresponding level of effectiveness in birth control was reached with regular contraceptive methods probably already at the end of the 1970 s. Because contraception in the younger age groups, where abortion was also more common, was mainly used to postpone having children until they were older, the increase in abortions apparently did not even have a temporary effect on the total number of children of these cohorts.

\section{References}

Central Statistical Office of Finland. 1978. Review of Vital Statistics 1961-1975. OSF VI A:139. Helsinki.

Council of Europe. 1991. Recent demographic developments in Europe. Strasbourg: Council of Europe.

Council of Europe. 1993. Recent demographic developments in Europe. Strasbourg: Council of Europe.

Easterlin, R. A. 1978. What will 1984 be like? Socioeconomic implications of recent twists in age structure. Demography 15 (4):397-432.

Easterlin, R. A. 1987. Birth and Fortune: The Impact of Numbers on Personal Welfare. Chicago, Ill: University of Chicago.

Finnäs, F. 1988. The fertility trends among married Finnish women born in 1932-58. Yearbook of Population Research in Finland 26:26-36.

Fougstedt, G. 1977. Trends and Factors of Fertility in Finland. Commentationes Scientiarum Socialium, vol. 7. Helsinki: Societas Scientiarum Fennica.

Henshaw, S.K. and E. Morrow. 1990. Induced Abortion: A World Review 1990 Supplement. New York: The Alan Guttmacher Institute.

van de Kaa, D. J. 1987. Europe's second demographic transition. Population Bulletin 42(1).

Lahti, R. 1973. Uusien abortti- ja steriloimislakien vaikutus maassamme (The effect of the new abortion and sterilization laws in our country). Suomen lääkärilehti 28(5): 303-314.

Leppo, K. 1978. Contraception in Finland: A Public Health Perspective. Publications of the Population Research Institute, Ser. D, No. 5. Helsinki: The Population Research Institute.

Lindgren, J. 1975. Suomalaisen syntyvyyden kehityskuva (Finnish fertility trends). Väestöntutkimuslaitoksen julkaisuja, sarja B, no. 38. Helsinki: Väestöntutkimuslaitos.

Lindgren, J. 1977. The increasing fertility in Finland. Yearbook of Population Research in Finland 15:65-72.

Lindgren, J. 1984. The fertility increase in Finland in 1982. Yearbook of Population Research in Finland $22: 77-83$.

Lindgren, J. and M. Ritamies. 1981. Population development in Finland in the 1970s. Yearbook of Population Research in Finland 19:11-27.

Myrskylä, P. 1976. Fertility. Central Statistical Office of Finland, Studies, No. 36. Helsinki: Central Statistical Office.

Notkola, I-L. 1994. Hedelmällisyys (Fertility). In: Suomen väestö (Finland's Population), edited by S. Koskinen et al, pp. 64-106. Helsinki: Gaudeamus.

Rasimus, A. 1993. Tilastoja raskauden keskeytyksistä (Statistics on induced abortions). In: Raskauden keskeytykset vuoteen 1991 Suomessa (Induced abortions in Finland until 1991). SVT Official statistics of Finland. Health 1993:3. Helsinki: National Research and Development Centre for Welfare and Health.

Ritamies, M. and E. Visuri. 1975. Suomalaisten perhekoko - sattuma vai suunnitelma (Finnish family size - an accident or planned). Väestöntutkimuslaitoksen julkaisusarja D, no.1. Helsinki: Population Research Institute.

Wiman, R. 1978. The impact of the post-war baby-boom in Finland. Yearbook of Population Research 16:83-98. 